\title{
Article \\ Facile Fabrication of Polyaniline/Graphene Composite Fibers as Electrodes for Fiber-Shaped Supercapacitors
}

\author{
Xuefei Yang ${ }^{1,+}$, Yihan Qiu ${ }^{1,+}$, Mei Zhang ${ }^{1, *}$, Liangjing Zhang ${ }^{2, *}$ and Hongwei Li $^{1}$ \\ 1 Beijing Key Laboratory of Clothing Materials R \& D and Assessment, Beijing Engineering Research Center of \\ Textile Nanofiber, School of Materials Design and Engineering, Beijing Institute of Fashion Technology, \\ Beijing 100029, China; xuefei2020@yeah.net (X.Y.); qiuyihan623@163.com (Y.Q.); \\ clylihongwei@bift.edu.cn (H.L.) \\ 2 Shenzhen Key Laboratory of Ultraintense Laser and Advanced Material Technology, Center for Advanced \\ Material Diagnostic Technology, Shenzhen Technology University, Shenzhen 518118, China \\ * Correspondence: 20140027@bift.edu.cn (M.Z.); zhangliangjing@sztu.edu.cn (L.Z.) \\ + These authors contributed equally.
}

check for updates

Citation: Yang, X.; Qiu, Y.; Zhang, M.; Zhang, L.; Li, H. Facile

Fabrication of Polyaniline/Graphene Composite Fibers as Electrodes for Fiber-Shaped Supercapacitors. Appl. Sci. 2021, 11, 8690. https://doi.org/ 10.3390/app11188690

Academic Editor: Andrew F. Burke

Received: 25 August 2021

Accepted: 15 September 2021

Published: 17 September 2021

Publisher's Note: MDPI stays neutral with regard to jurisdictional claims in published maps and institutional affiliations.

Copyright: (C) 2021 by the authors Licensee MDPI, Basel, Switzerland. This article is an open access article distributed under the terms and conditions of the Creative Commons Attribution (CC BY) license (https:/ / creativecommons.org/licenses/by/ $4.0 /)$.

\begin{abstract}
Graphene fiber-based supercapacitors are known as the potential energy resources for wearable/flexible electronics. However, increasing their specific capacitance and energy density remains a significant challenge. This paper indicates a double layer capacitance of the graphene nanosheets accompanied by pseudocapacitive behavior of the polyaniline to prepare composite fibers with high capacitive response. The polyaniline/graphene composite fibers (PANI/GFs) were synthesized by the self-assembled strategy and chemical reduction by HI. The wrinkle architecture of graphene nanosheets and uniform dispersion of the polyaniline are beneficial to increase the internal electroactive sites and provide a stable structure for the composite fibers. The constructed fiber-shaped supercapacitors with solid-state electrolyte deliver an excellent areal specific capacitance of $370.2 \mathrm{mF} \mathrm{cm}^{-2}$ and an outstanding areal energy density of $12.9 \mu \mathrm{W} \mathrm{h} \mathrm{cm}{ }^{-2}$. The current work reveals the attractive potential of the as-synthesized composite fibers for constructing fiber-shaped supercapacitors with distinguished electrochemical performance, which can be applied in future flexible electronics.
\end{abstract}

Keywords: graphene; polyaniline; composite fibers; flexible supercapacitors; energy density

\section{Introduction}

The rapid development of wearable/flexible electronics has tremendously increased the attraction of flexible power supplies/devices that are lightweight and flexible [1-3]. Among various flexible power sources, fiber-shaped supercapacitors not only possess these superiorities of lightweight, small, and mechanical flexibility, but also can be easily woven into textiles, highlighting great advantages in the future flexible, portable, and wearable electronics field [4-6]. However, compared with lithium ion batteries or traditional supercapacitors, fiber-shaped supercapacitors display much lower specific capacitance and energy density, which impede their widespread application $[7,8]$. As we know, the energy density of supercapacitors is proportional to its capacitance depending on the intrinsic charge storage capabilities of electrode materials $[9,10]$. Therefore, much effort has been committed to exploiting new structural electrode materials to construct high electrochemical performance fiber-shaped supercapacitors for wearable/flexible electronic devices.

For fiber-shaped supercapacitors, carbon-based materials are the most commonly utilized as electrodes because of their many characteristics including exceptional electric conductivity, large surface area, lightweight, low-cost, and chemical stability, as well as wide operating temperature range, especially graphene fibers [11,12]. In 2011, Gao and his coworkers exploited graphene oxides as a liquid crystal spinning solution, and first prepared graphene fibers by the wet-spinning method and chemical reduction [13]. Graphene 
fibers have been utilized extensively as flexible electrodes for wearable supercapacitors, exhibiting flexibility, lightweight, and representative double layer capacitor behavior. The charge-storage ability of the supercapacitors based on carbon materials is mainly dominated by the effective specific surface area. However, the graphene fibers exhibit graphite-like structures because of the strong $\pi-\pi$ bonding existing in graphene nanosheets, which results in a low specific surface area and a poor wettability of the electrolyte $[8,14,15]$. The limited specific capacitance and poor energy density of the pure graphene fibers restrict further application in future wearable/flexible electronics [16-18]. Therefore, some materials with pseudocapacitive properties, for example, transition metal oxides [19-22], metal sulfides [14,23-25], and conducting polymers [9,26-28], have been added into graphene fibers or other carbon materials to promote specific capacitance and energy density. Polyaniline is a potential candidate for the high theoretical specific pseudocapacitance and good electrical conductivity $[29,30]$. Polyaniline is combined with graphene fibers, increasing the electroactive sites and providing a stable structure of composite fiber flexible electrodes in electrochemical measurement processes.

In this research, polyaniline/graphene composite fibers (PANI/GFs) were constructed by the self-assembly method and chemical reduction processes. The synthesis processes are shown in Figure 1. The polyaniline obtained by chemical polymerization exists in graphene fibers, which could impede the aggregation of graphene nanosheets and guarantee the uniform distribution of PANI in the composite fibers. These fiber-shaped supercapacitors consisting of PANI/GFs display an outstanding areal specific capacitance of $370.2 \mathrm{mF} \mathrm{cm}^{-2}$ and an excellent energy density of $12.9 \mu \mathrm{W} \mathrm{h} \mathrm{cm}{ }^{-2}$ when the power density is up to $25.3 \mu \mathrm{W} \mathrm{cm}{ }^{-2}$ on PVA $/ \mathrm{H}_{2} \mathrm{SO}_{4}$ gel electrolyte. Graphene composite fibers exhibit potential advantages as fiber electrode for wearable energy storage systems, boosting the further application of graphene fibers in prospective flexible/wearable electronic devices.

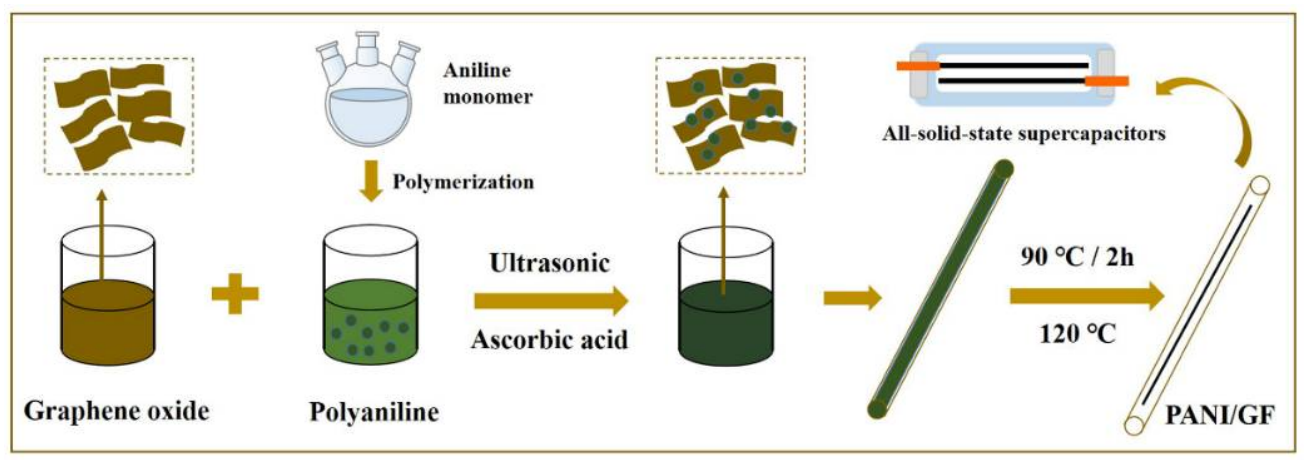

Figure 1. Scheme of the PANI/GF forming mechanism.

\section{Materials and Methods}

\subsection{Synthesis of Materials}

\subsubsection{Preparation of Polyaniline}

Here, $1 \mathrm{mmol}$ aniline monomer was poured into a $50 \mathrm{~mL} 1 \mathrm{M} \mathrm{HCl}$ solution by stirring for $5 \mathrm{~min}$, and ammonium peroxydisulfate (APS) was dissolved in $1 \mathrm{M} \mathrm{HCl}$ solution to obtain a uniform APS solution. Then, aniline solution was slowly poured into the APS solution above by continuous stirring and the chemical reaction was conducted at room temperature for $12 \mathrm{~h}$; the molar ratio of APS to aniline was 1:1. The obtained polyaniline (PANI) nanomaterials were cleaned by the deionized water under high-speed centrifugal processes. The formed PANI suspension was dried by oven at $60^{\circ} \mathrm{C}$ and the weight percentages of PANI were calculated to be $8 \%$.

\subsubsection{Preparation of Polyaniline/Graphene Composite Fibers}

All the chemicals were of analytical grade and utilized as received, without further purification. As shown in Figure 1, the synthesis of polyaniline/graphene composite fibers (PANI/GF) had two steps: first, the graphite oxides (GO) suspension was prepared by 
a modified Hummers method, which maintains excellent stability at room temperature. Then, $10 \mathrm{~mL}$ GO solution of $7 \mathrm{mg} \mathrm{mL}^{-1}$ was placed in an ultrasonic bath for $30 \mathrm{~min}$, ensuring the good uniformity of the solution. Further, 0, 0.1, 0.2, or $0.3 \mathrm{~g}$ PANI suspensions were mixed with GO solution and mixed under ultrasonication for another $1.5 \mathrm{~h}$. Then, $0.1 \mathrm{~g}$ reducing agent was added into the GO and PANI suspension to obtain homogeneous mixtures. Second, the mixture suspension was injected into a PTFE tube, which was sealed, and maintained at $90^{\circ} \mathrm{C}$ for $2 \mathrm{~h}$ to preliminarily form gel-fibers, and then at $120^{\circ} \mathrm{C}$ until fibers fully formed. The formation of PANI/GF was mainly ascribed to the capillary forces and surface tension guided graphene nanosheet interactions. The fabricated fibers were named as GF, PANI/GF1, PANI/GF2, and PANI/GF3, respectively, according to different adding amounts of PANI nanomaterials $(0,0.1,0.2$, and $0.3 \mathrm{~g}$ PANI suspension with $8 \%$ weight percentages).

\subsection{Characterization}

The morphologies of graphene-based fibers were characterized using scanning electron microscopy (SEM, JEOL JSM-7600F). The TGA (STA 449F3 + ASC) analysis was conducted under a nitrogen atmosphere with a heating rate of $10{ }^{\circ} \mathrm{C} / \mathrm{min}$, increasing between $35^{\circ} \mathrm{C}$ and $1000{ }^{\circ} \mathrm{C}$. Fourier transform infrared spectra (FTIR, Nicolet Nexus 670) were recorded from 400 to $4000 \mathrm{~cm}^{-1}$. Additionally, other information of the samples was observed via Raman (JY HR800), XPS (ESCALAB 250), and XRD.

\subsection{Construction of Fiber-Shaped Supercapacitors and Electrochemical Measurements}

The symmetric fiber-shaped supercapacitor was constructed via covering with gel-like solid-state electrolyte (PVA/ $\left.\mathrm{H}_{2} \mathrm{SO}_{4}\right)$ on two parallel PANI/GF electrodes fixed on a flexible PDMS substrate, and the use of a gel-like electrolyte can protect the electrodes from short circuit. The PVA $/ \mathrm{H}_{2} \mathrm{SO}_{4}$ gel electrolyte was prepared by adding $12 \mathrm{~g}$ PVA and $12 \mathrm{~g} \mathrm{H}_{2} \mathrm{SO}_{4}$ into $120 \mathrm{~mL}$ deionized water, and the mixed solution was heated at $95^{\circ} \mathrm{C}$ accompanied by continuously stirring until the electrolyte became clear.

For the assembled fiber-shaped supercapacitors, a CHI660E electrochemical workstation was used to evaluate the electrochemical performance including CV, EIS, and galvanostatic charge/discharge cycling. The areal specific capacitance of the flexible supercapacitor was obtained from the following equation: $=\frac{4 I \Delta t}{\Delta V A}$, where $I, \Delta t, \Delta V$, and $\mathrm{A}\left(\mathrm{cm}^{2}\right)$ are the discharge current $(\mathrm{mA})$, the discharge time $(\mathrm{s})$, the voltage range $(\mathrm{V})$, and the total surface area of two electrodes, respectively [31]. The energy density $(E)$ and power energy $(P)$ are usually calculated by equations of $E=\frac{C V^{2}}{8}$ and $=\frac{E}{\Delta t}$, where $C\left(\mathrm{mF} \mathrm{cm}^{-2}\right), V(\mathrm{~V})$, and $\Delta \mathrm{t}(\mathrm{s})$ represent the areal specific capacitance, the operated voltage, and the discharge time, respectively [32].

\section{Results and Discussion}

The amount of PANI in composite fibers is a significant factor for the electrochemical performance of the flexible supercapacitors. This work reports composite fibers with different loading amounts of PANI. The PANI/GF prepared with $0.2 \mathrm{~g}$ PANI suspension displays the best electrochemical performance, and the following characterizations are obtained from the composite fibers with $0.2 \mathrm{~g}$ PANI suspension. Figure 2 shows the TGA profiles of PANI, GF, and PANI/GF. The mass decreasing around $100{ }^{\circ} \mathrm{C}$ in the PANI curve is ascribed to the loss of the $\mathrm{H}_{2} \mathrm{O}$ molecular, and a sharp change at about $500{ }^{\circ} \mathrm{C}$ exists in the TGA curve of the PANI [33-36]. The pure PANI still maintains $45 \%$ weight at $1000{ }^{\circ} \mathrm{C}$, suggesting the carbonization of phenyl [37]. After the same procedure, the weight loss of the GF and PANI/GF is approximately $35.6 \%$ and $39.2 \%$, respectively. Therefore, the corresponding PANI weight ratio of PANI/GF is $18.6 \%$. This result is consistent with that calculated by adding the amount of PANI in the synthesis process. 


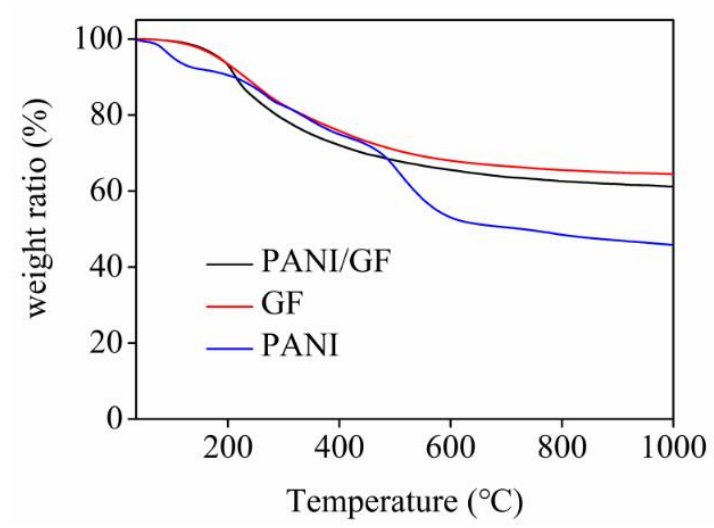

Figure 2. Thermal gravimetric analysis (TGA) profiles of PANI/GF, GF, and PANI.

In Figure 3, SEM shows the detailed morphology and architecture of the as-synthesized GF and PANI/GF. The diameter of GF is approximately $160 \mu \mathrm{m}$, and the GF possess a coarse surface with a wrinkled and crumpled architecture (Figure $3 a, b)$. The cross-section morphology of GF exhibits a hierarchical structure (Figure 3c). These morphological and structure features help in the transportation and storage of massive electrons, which can fully utilize the electrical double layer capacitance to improve electrochemical performance. In Figure 3d-f, PANI/GF exhibits approximate surface morphology and architecture at the microscale compared with GF. PANI nanomaterials can be found on the surface and cross section of the composite fibers, and the existence of PANI nanomaterials in the composite fibers changes the hierarchical structure (Figure 3g,h). Energy-dispersive $X-$ ray spectroscopic element distribution maps of $C, N$, and $\mathrm{O}$ clearly verify the uniform distribution of the PANI nanomaterials in the composite fibers, as shown in Figure 3i.

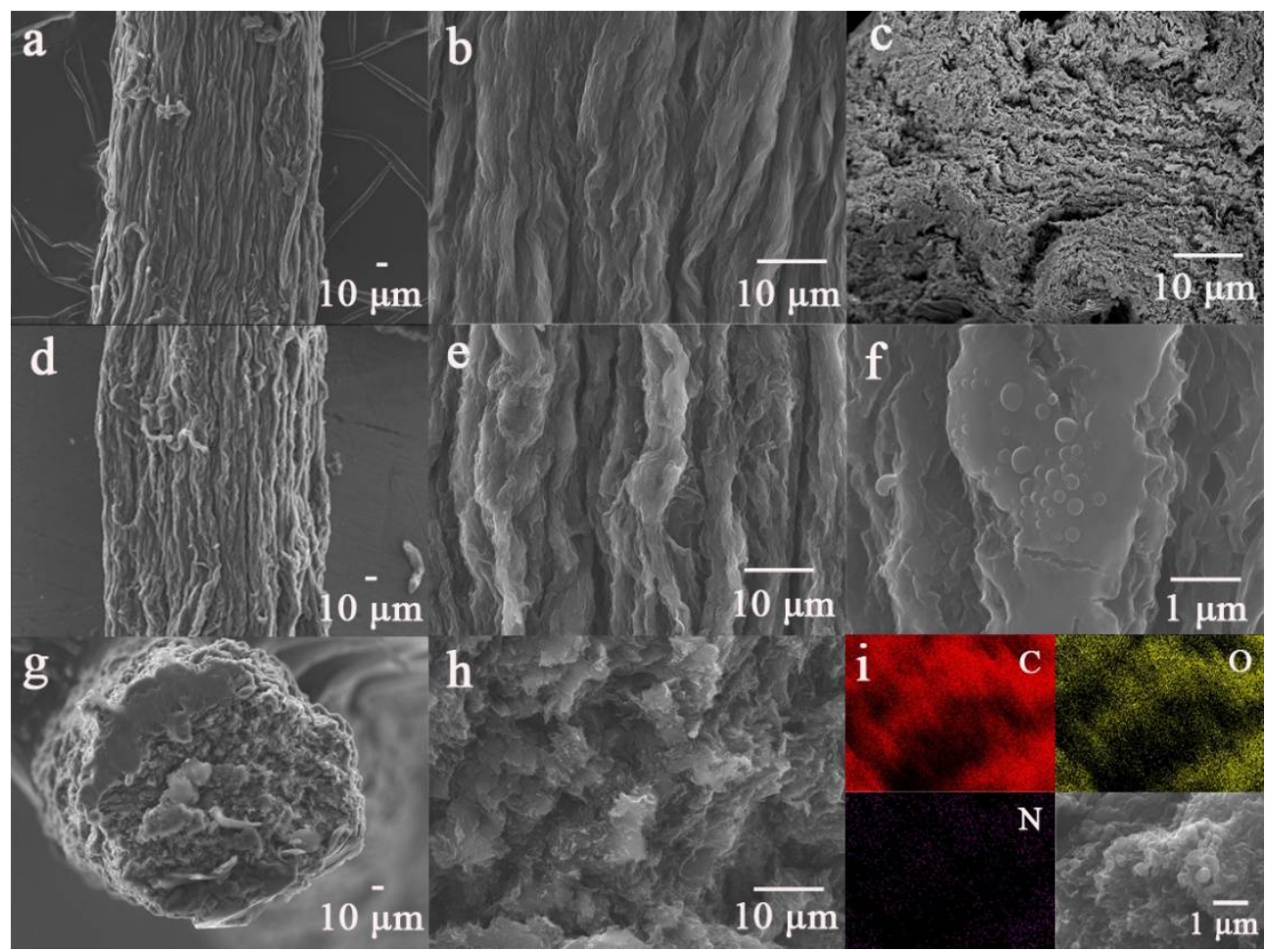

Figure 3. Surface (a,b) and cross-sectional (c) SEM images of GF, and surface (d-f) and cross-sectional (g,h) SEM images of PANI/GF at low and high magnifications. (i) SEM image and EDS element distribution mapping of $\mathrm{C}, \mathrm{N}$, and $\mathrm{O}$. 
In Figure 4, there are two characteristic peaks of $\mathrm{D}$ and $\mathrm{G}$ associated with graphene nanosheets in the Raman curves of GO, GF, and PANI/GF, which are ascribed to the reduction in the size of the in-plane vibration of $\mathrm{sp}^{2}$ carbon atoms and the K-point phonons of $A_{1 g}$ symmetry $[38,39]$. The information corresponding to carbon structural changes can be obtained from Raman spectra [40]. For the PANI/GF, besides the D and G bands of GF, the typical peaks at $575 \mathrm{~cm}^{-1}$ and $1169 \mathrm{~cm}^{-1}$ relate to the out-of-plane $\mathrm{C}-\mathrm{H}$ deformation and $\mathrm{C}-\mathrm{H}$ binding of the quinoid ring, respectively $[25,32,35]$.

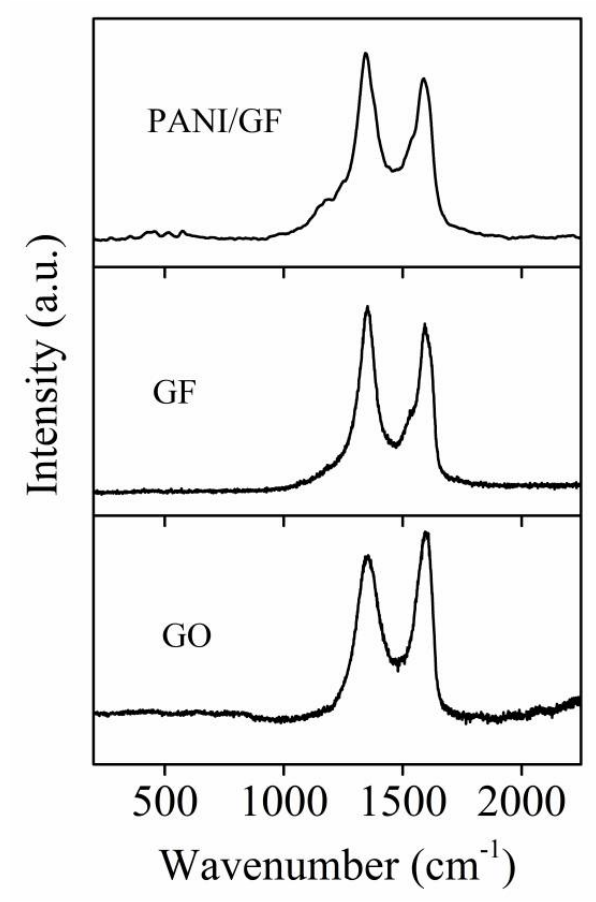

Figure 4. Raman curves of GO, GF, and PANI/GF.

As shown in Figure 5, the XRD patterns of GO, GF, and PANI/GF are analyzed. GO has a typical diffraction peak (001) located at $11.6^{\circ}$, while GF shows a characteristic peak at $25.5^{\circ}$ related to the (002) plane of stacked graphene sheets $[29,41]$. The XRD pattern of PANI/GF and GF indicate similar features, and the (002) diffraction peak reveals the superimposed intensity of GF and PANI, which is due to a typical peak near $25^{\circ}$ for both $[25,42]$.

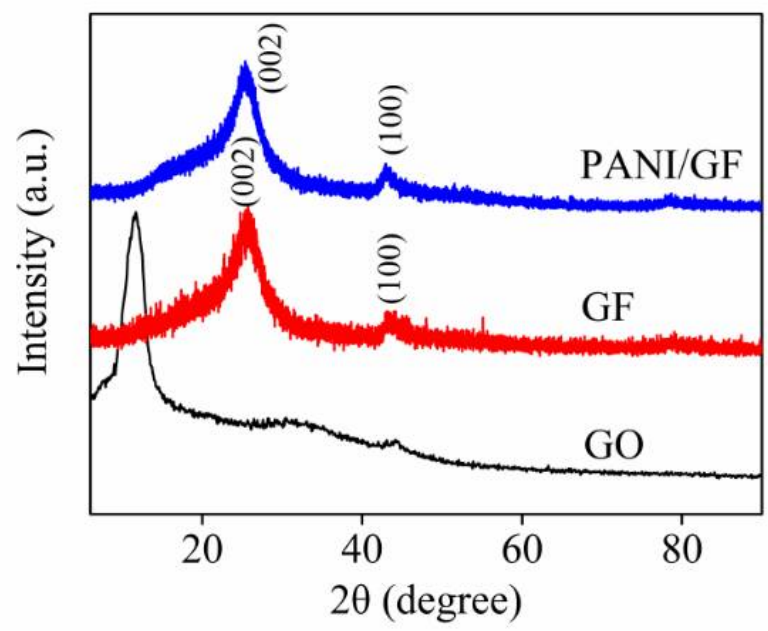

Figure 5. XRD spectra of GO, GF, and PANI/GF. 
Additionally, high-resolution XPS of the C1s and N1s peaks can show electronic states between elements. In Figure 6a, the peaks at 284.7, 286, 287, and $288.3 \mathrm{eV}$ were assigned to the $\mathrm{C}-\mathrm{C}$ in the aromatic rings, $\mathrm{C}-\mathrm{O}$ of epoxy, $\mathrm{C}=\mathrm{O}$, and $\mathrm{O}=\mathrm{C}-\mathrm{OH}$ groups, respectively [43]. Compared with the GO spectrum, the oxygen content in GF and PANI/GF are decreased significantly (Figure $6 b, c$ ). As shown in Figure 6d, the N1s of PANI/GF contains three kinds electronic states of the quinoid imine $(-\mathrm{N}=)$ at 398.5 , the benzenoid amine $(-\mathrm{NH}-)$ at 399.1, and the nitrogen cationic radical $\left(\mathrm{N}^{+}\right)$at $400.5 \mathrm{eV}$, respectively [26,44]. The XPS results and the XRD spectra indicate the PANI structure in the composite fibers.
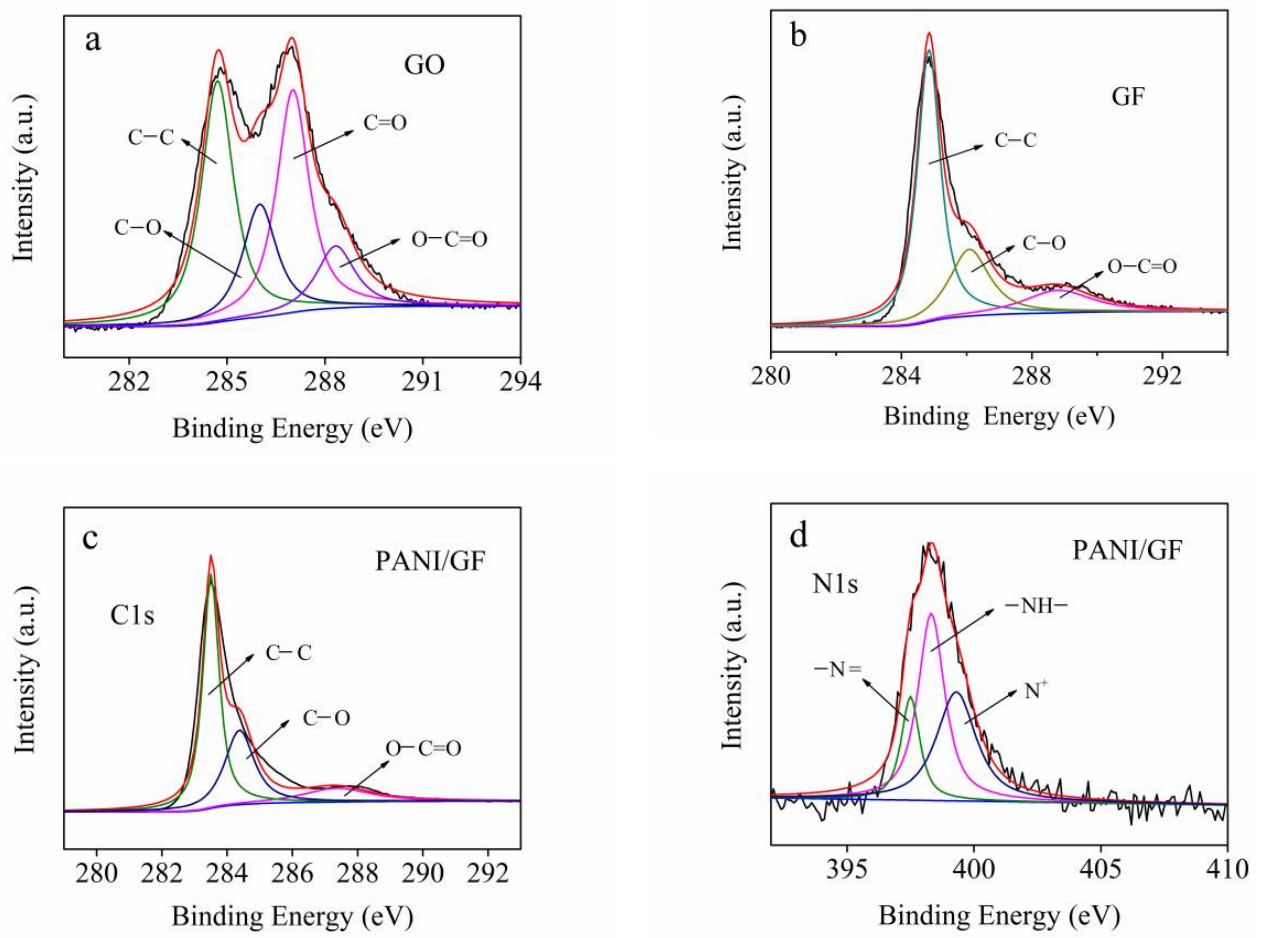

Figure 6. XPS C1s spectra of GO (a), GF (b), and PANI/GF (c), as well as XPS N1s curve of PANI/GF (d).

We evaluated in detail the electrochemical properties of fiber-shaped flexible supercapacitors assembled by covering the gel-state polyvinyl alcohol supported $\mathrm{H}_{2} \mathrm{SO}_{4}$ electrolyte on the as-synthesized graphene-based composite fibers in a two-electrode system. Figure $7 \mathrm{a}-\mathrm{c}$ show cyclic voltammogram $(\mathrm{CV})$ profiles of the flexible supercapacitors constructed by GF and PANI/GF, which are measured in a narrow electrochemical window of $0-0.8 \mathrm{~V}$ at various scan rates of $10 \mathrm{mVs}^{-1}, 20 \mathrm{mVs}^{-1}, 30 \mathrm{mVs}^{-1}, 40 \mathrm{mVs}^{-1}$, and $50 \mathrm{mVs}^{-1}$. The $\mathrm{CV}$ analysis is beneficial to further understanding of the electrochemical behavior and stability during electrochemical measurement processes [45]. As shown in Figure $7 \mathrm{a}, \mathrm{b}$, with scan rates increasing, the $\mathrm{CV}$ curves of the GF also display an approximate rectangular shape (Figure 7a), indicating apparent electrochemical double-layer capacitive behavior. Figure $7 \mathrm{~b}$ shows the typical redox peaks and rectangle shape in the $\mathrm{CV}$ curves of PANI/GF, and the capacitance of the as-constructed flexible energy storage devices consists of pseudocapacitance and double-layer capacitance [43]. Notably, the area of the CV curves of PANI/GF almost increases with the scan rate in the proportion, revealing that the specific capacitance of PANI/GF is not influenced by the scan rate. Figure 7c displays the $\mathrm{CV}$ profiles of GF and PANI/GF at $10 \mathrm{mVs}^{-1}$. The $\mathrm{CV}$ profiles of PANI/GF display a larger integrated $\mathrm{CV}$ area with obvious redox peaks compared with those of GF, indicating faster ion diffusion and higher energy storage properties. The enhanced electrochemical performance of PANI/GF is mainly ascribed to the more internal electroactive sites and the structural stability of PANI/GF [46]. In addition, Figure 7d shows EIS of GF and PANI/GF to evaluate the ion transport mechanisms, which can indicate the contact between the 
electrode and electrolyte. In the high frequency region, the x-intercept of PANI/GF is significantly smaller than that of GF. This is because the doping of conductive polymer increases its conductivity and reduces the corresponding equivalent resistance value. The low frequency curve of PANI/GF has a larger slope $[9,10,47]$. The greater slope of the curve of PANI/GF implies better capacitive behavior and fast ion migration capability, improving the electrochemical performance $[17,32,48]$.
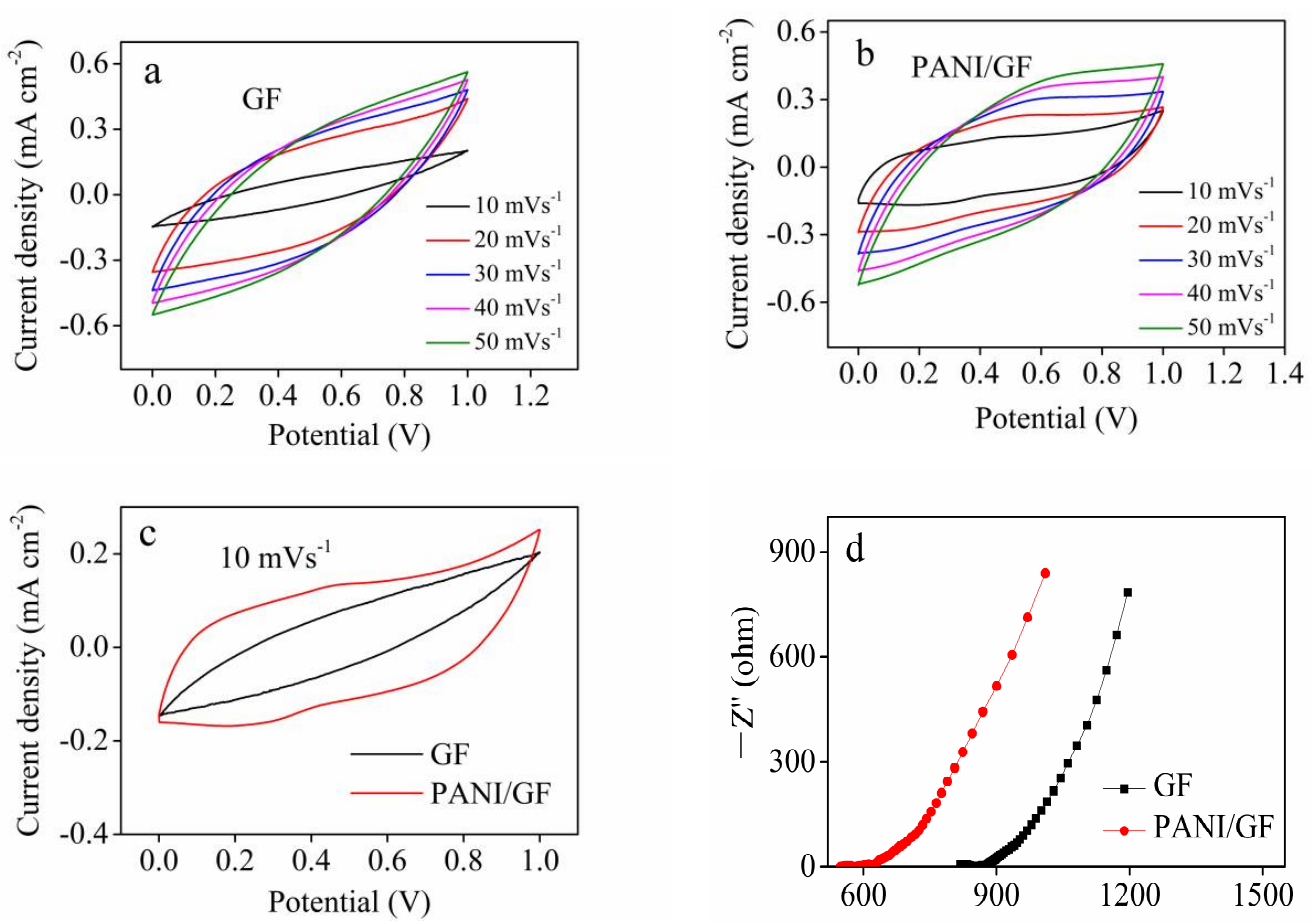

Figure 7. CV profiles of (a) GF and (b) PANI/GF at various scan rates of 10, 20, 30, 40, and $50 \mathrm{mVs}^{-1}$; (c) CV curves of GF and PANI/GF at $10 \mathrm{mVs}^{-1}$; and (d) EIS analysis of fiber-shaped flexible supercapacitors.

Figure 8a displays the GCD profiles of GF and PANI/GF with different PANI content at a current density of $0.05 \mathrm{~mA} \mathrm{~cm}^{-2}$. PANI/GF2 prepared with $19 \%$ PANI displays the largest capacitance $\left(370.2 \mathrm{mF} \mathrm{cm}{ }^{-2}\right)$ at a current density of $0.05 \mathrm{~mA} \mathrm{~cm}^{-2}$, which is better than those of PANI/GF1 $\left(196.4 \mathrm{mF} \mathrm{cm}^{-2}\right)$, PANI/GF3 $\left(85 \mathrm{mF} \mathrm{cm}^{-2}\right)$, and GF $\left(68.8 \mathrm{mF} \mathrm{cm}^{-2}\right)$. The specific capacitances derived from the discharge profiles (Figure $8 \mathrm{a}$ ) are displayed in Figure 8b. The GCD curves of PANI/GF-based fiber-shaped supercapacitors are symmetric and indicate approximately electrochemical behavior at different current densities (Figure 8c), indicating an excellent reversibility and efficient ion/charge transport of the fiber-shaped supercapacitors [48]. The fiber-shaped supercapacitors fabricated by PANI/GF display specific areal capacitances of $370.2,330.8,229.6,145.2$, and $96.0 \mathrm{mF} \mathrm{cm}^{-2}$ (104.8, 93.7, 65.0, and $27.2 \mathrm{~F} \mathrm{~cm}^{-3}$ for specific volumetric capacitances) at 0.05, 0.1, 0.2, 0.3, and $0.4 \mathrm{~mA} \mathrm{~cm}^{-2}$, respectively, as shown in Figure $8 \mathrm{~d}$.

To evaluate the practical application of PANI/GF-based supercapacitors, the long-term cycling stability at a current density of $0.35 \mathrm{~mA} \mathrm{~cm}{ }^{-2}$ under continuous charge/discharge operation is shown in Figure 9a. Satisfactorily, PANI/GF exhibits a steadily continuous charge/discharge process for 2365 cycles without any noticeable degradation, which maintains a capacitance retention of $96 \%$. In Figure 9b, surface (I-П) and cross-sectional (III-IV) SEM images of PANI/GF images are obtained after a long-term cycling test. The little gel-like electrolyte is found on the surface of PANI/GF. The SEM images exhibit approximate surface morphology and architecture at the microscale compared with PANI/GF before cycling measurement, which indicates excellent cycling stability of PANI/GF-based supercapacitors. 

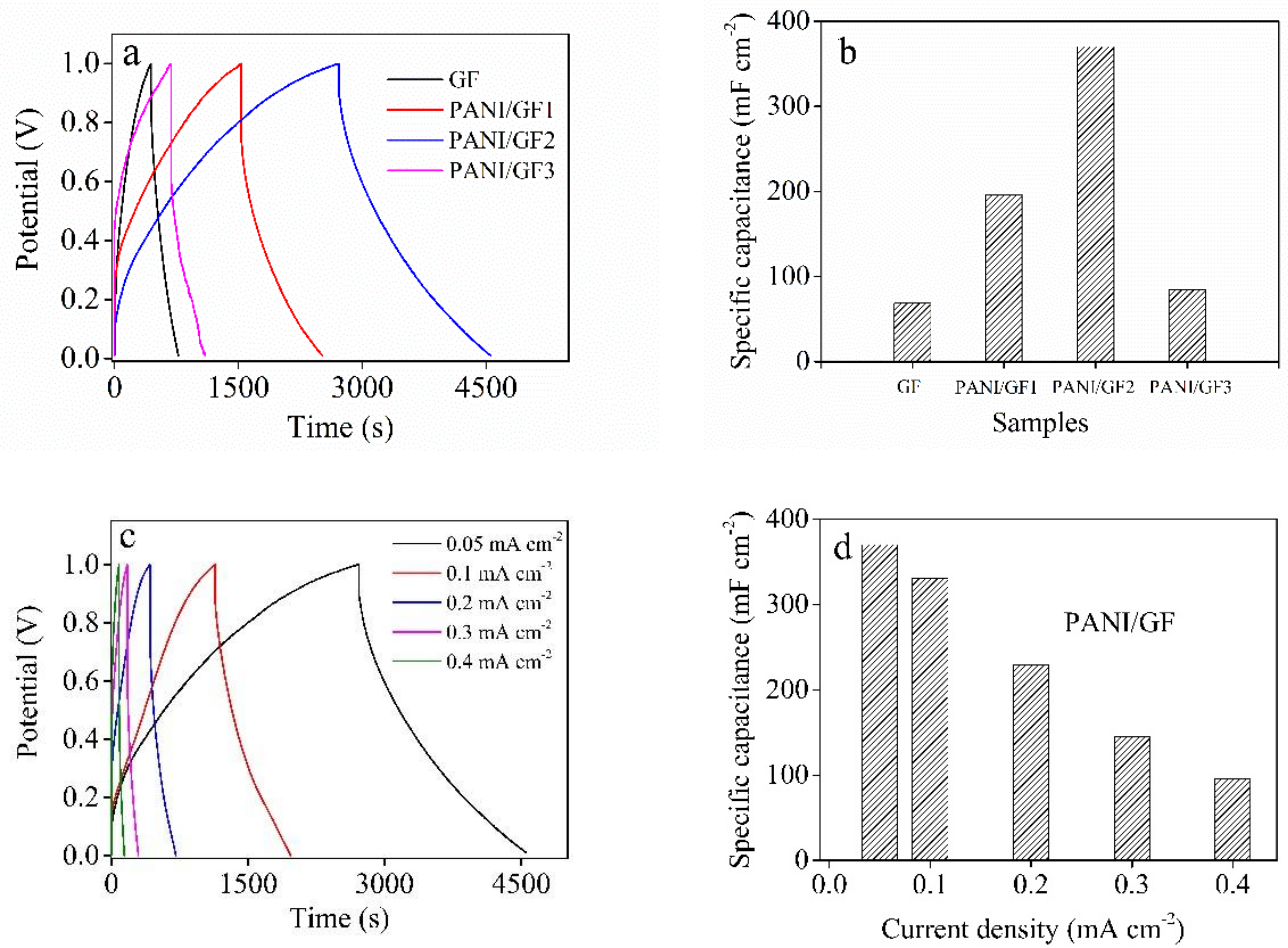

Figure 8. (a) GCD profiles and (b) specific capacitance of GF, PANI/GF1, PANI/GF2, and PANI/GF3 at a current density of $0.05 \mathrm{~mA} \mathrm{~cm}^{-2}$; (c) galvanostatic charge/discharge (GCD) curves; and (d) specific capacitance of PANI/GF at various current densities of $0.05,0.1,0.2,0.3$, and $0.4 \mathrm{~mA} \mathrm{~cm}^{-2}$.
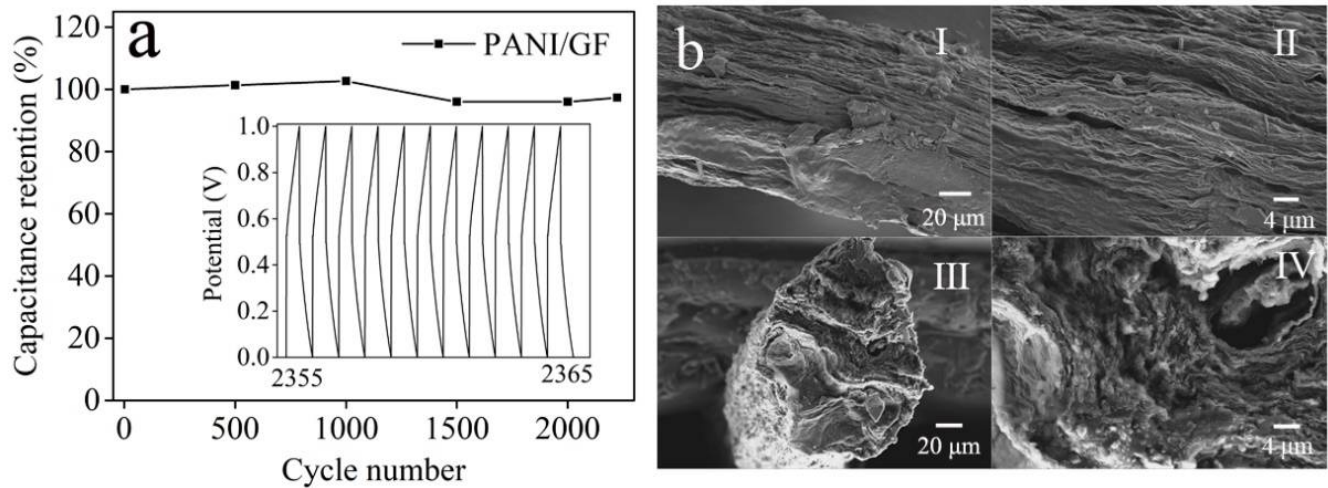

Figure 9. (a) Cyclic stability of PANI/GF at a current density of $0.35 \mathrm{~mA} \mathrm{~cm}{ }^{-2}$ under continuous charge/discharge operation. Inset: GCD curves from the 2355th to 2365th cycles. (b) Surface (I,I) and cross-sectional (III,IV) SEM images of PANI/GF.

The fiber-shaped supercapacitors display good specific capacitance and excellent energy density. Many publications report pure graphene fibers or conducting polymer/graphene composite fibers as electrode materials for flexible supercapacitors, and these are summarized in Table 1. In brief, the fiber-shaped supercapacitors constructed by PANI/GF and gel-like electrolyte indicate good electrochemical properties because of the more internal electroactive sites, the designed wrinkling, and the stable architecture between PANI and graphene sheets in composite fibers. This work will provide a fabrication method and theory foundation for high-performance graphene composite fiber-based flexible supercapacitors for future wearable electronic devices. 
Table 1. Electrochemical properties of graphene fiber-based flexible supercapacitors.

\begin{tabular}{|c|c|c|c|c|c|}
\hline $\begin{array}{l}\text { Electrode } \\
\text { Materials }\end{array}$ & Electrolyte & $\begin{array}{c}\text { Areal Capacitance or } \\
\text { Volumetric } \\
\text { Capacitance }\end{array}$ & Power Density & Energy Density & Ref. \\
\hline GF or PANI/GF & $\mathrm{PVA} / \mathrm{H}_{3} \mathrm{PO}_{4}$ & 3.3 or $66.6 \mathrm{mF} \mathrm{cm}^{-2}$ & - & - & [49] \\
\hline Graphene fiber & $\mathrm{PVA} / \mathrm{H}_{2} \mathrm{SO}_{4}$ & $226 \mathrm{mF} \mathrm{cm}^{-3}$ & $57.7 \mathrm{~mW} \mathrm{~cm}^{-3}$ & $7.03 \mathrm{~mW} \mathrm{~h} \mathrm{~cm}^{-3}$ & [50] \\
\hline Graphene fiber & $\begin{array}{c}\mathrm{PVA} / \mathrm{H}_{2} \mathrm{SO}_{4} \text { or } \\
\mathrm{PVDF} / \mathrm{EMIMBF}_{4}\end{array}$ & $36.25 \mathrm{mF} \mathrm{cm}^{-2}$ & $0.02 \mathrm{~mW} \mathrm{~cm}^{-2}$ & 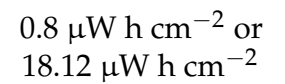 & [15] \\
\hline RGO/PEDOT fiber & $\mathrm{PVA} / \mathrm{H}_{3} \mathrm{PO}_{4}$ & $304.5 \mathrm{mF} \mathrm{cm}^{-2}$ & $66.5 \mu \mathrm{W} \mathrm{cm} \mathrm{cm}^{-2}$ & $27.1 \mu \mathrm{W} \mathrm{h} \mathrm{cm}-2$ & [9] \\
\hline rGO/PEDOT fiber & $\mathrm{PVA} / \mathrm{H}_{3} \mathrm{PO}_{4}$ & $131 \mathrm{mF} \mathrm{cm}^{-2}$ & $125 \mu \mathrm{W} \mathrm{cm}{ }^{-2}$ & $4.55 \mu \mathrm{W} \mathrm{h} \mathrm{cm}{ }^{-2}$ & [51] \\
\hline $\mathrm{PPy} / \mathrm{GF}$ & $\mathrm{PVA} / \mathrm{H}_{2} \mathrm{SO}_{4}$ & $95-105 \mathrm{mF} \mathrm{cm}{ }^{-2}$ & - & $6.6-9.7 \mu \mathrm{W} \mathrm{h} \mathrm{cm}{ }^{-2}$ & [52] \\
\hline PANI/G fiber & $\begin{array}{c}\text { PVA } / \mathrm{H}_{3} \mathrm{PO}_{4} \text { or } \\
\text { EMITFSI/PVDF-HFP }\end{array}$ & $230 \mathrm{mF} \mathrm{cm}^{-2}$ & $15 \mathrm{~mW} \mathrm{~cm}^{-2}$ & $37.2 \mu \mathrm{Wh} \mathrm{cm}{ }^{-2}$ & [32] \\
\hline PANI/GF & $\mathrm{PVA} / \mathrm{H}_{2} \mathrm{SO}_{4}$ & $357.1 \mathrm{mF} \mathrm{cm}^{-2}$ & $0.23 \mathrm{~mW} \mathrm{~cm}^{-2}$ & $7.93 \mu \mathrm{Wh} \mathrm{cm} \mathrm{h}^{-2}$ & [48] \\
\hline PANI/GF & $\begin{array}{c}\text { PVA } / \mathrm{H}_{3} \mathrm{PO}_{4} \text { or } \\
\text { EMITFSI/PVDF-HFP }\end{array}$ & $87.8 \mathrm{mF} \mathrm{cm}^{-2}$ & $0.23 \mathrm{~mW} \mathrm{~cm}^{-2}$ & $12.2 \mu \mathrm{W} \mathrm{h} \mathrm{cm}{ }^{-2}$ & [11] \\
\hline PANI/GF & $\mathrm{PVA} / \mathrm{H}_{2} \mathrm{SO}_{4}$ & $370.2 \mathrm{mF} \mathrm{cm}^{-2}$ & $25.3 \mu \mathrm{W} \mathrm{cm}-2$ & $12.9 \mu \mathrm{W} \mathrm{h} \mathrm{cm}{ }^{-2}$ & This work \\
\hline
\end{tabular}

\section{Conclusions}

In summary, this paper proposes a double layer capacitance of the chemically reduced graphene oxides accompanied by pseudocapacitive behavior of polyaniline to produce composite fibers with a high capacitive response. We synthesized polyaniline/graphene composite fibers (PANI/GFs) by the self-assembly method and chemical reduction processes. The composite fiber-shaped supercapacitors with solid-state electrolyte deliver high area specific capacitance of $370.2 \mathrm{mF} \mathrm{cm}^{-2}$ and energy density of $12.9 \mu \mathrm{W} \mathrm{h} \mathrm{cm}{ }^{-2}$ at the power density of $25.3 \mu \mathrm{W} \mathrm{cm}{ }^{-2}$, which is mainly attributed to the crumpled morphology, the more internal electroactive sites, and the structural stability of the polyaniline in the composite fibers. The current work highlights the excellent potential of the as-constructed fiber-shaped supercapacitors for wearable/flexible electronic devices.

Author Contributions: X.Y. synthesized and characterized the samples. Y.Q. analyzed the data. M.Z. analyzed the data and wrote the paper. L.Z. contributed reagents/materials/analysis tools. H.L. designed the experiments and reviewed the paper. All authors have read and agreed to the published version of the manuscript.

Funding: This work was supported by the National Natural Science Foundation of China (No. 5200031283), the Key Program of Science and Technology Project of Beijing Institute of Fashion Technology (2020A-01), the Guangdong Province University Young Innovative Talents Program (2018KQNCX404), and the Post-doctoral research project of SZTU (W201960002440008).

Conflicts of Interest: The authors declare no conflict of interest.

\section{References}

1. Zhou, Y.; Wang, C.H.; Lu, W.; Dai, L. Recent Advances in Fiber-Shaped Supercapacitors and Lithium-Ion Batteries. Adv. Mater. 2020, 32, e1902779. [CrossRef] [PubMed]

2. Liao, M.; Ye, L.; Zhang, Y.; Chen, T.; Peng, H. The Recent Advance in Fiber-Shaped Energy Storage Devices. Adv. Electron. Mater. 2019, 5, 1800456. [CrossRef]

3. Li, L.; Lou, Z.; Chen, D.; Jiang, K.; Han, W.; Shen, G. Recent Advances in Flexible/Stretchable Supercapacitors for Wearable Electronics. Small 2018, 14, e1702829. [CrossRef] [PubMed]

4. Chen, D.; Jiang, K.; Huang, T.; Shen, G. Recent Advances in Fiber Supercapacitors: Materials, Device Configurations, and Applications. Adv. Mater. 2020, 32, e1901806. [CrossRef] [PubMed]

5. Zhai, S.; Karahan, H.E.; Wang, C.; Pei, Z.; Wei, L.; Chen, Y. 1D Supercapacitors for Emerging Electronics: Current Status and Future Directions. Adv. Mater. 2019, 32, e1902387. [CrossRef] [PubMed]

6. Tebyetekerwa, M.; Marriam, I.; Xu, Z.; Yang, S.; Zhang, H.; Zabihi, F.; Jose, R.; Peng, S.; Zhu, M.; Ramakrishna, S. Critical insight: Challenges and requirements of fibre electrodes for wearable electrochemical energy storage. Energy Environ. Sci. 2019, 12, 2148-2160. [CrossRef] 
7. Zhu, Y.H.; Yang, X.Y.; Liu, T.; Zhang, X.B. Flexible 1D Batteries: Recent Progress and Prospects. Adv. Mater. 2020, 32 , e1901961. [CrossRef]

8. Chen, L.; Liu, Y.; Zhao, Y.; Chen, N.; Qu, L. Graphene-based fibers for supercapacitor applications. Nanotechnology 2016, $27,032001$. [CrossRef]

9. Qu, G.; Cheng, J.; Li, X.; Yuan, D.; Chen, P.; Chen, X.; Wang, B.; Peng, H. A Fiber Supercapacitor with High Energy Density Based on Hollow Graphene/Conducting Polymer Fiber Electrode. Adv. Mater. 2016, 28, 3646-3652. [CrossRef]

10. Cheng, H.; Meng, J.; Wu, G.; Chen, S. Hierarchical Micro-Mesoporous Carbon-Framework-Based Hybrid Nanofibres for HighDensity Capacitive Energy Storage. Angew. Chem. Int. Ed. Engl. 2019, 58, 17465-17473. [CrossRef]

11. Zhang, M.; Wang, X.; Yang, T.; Zhang, P.; Wei, X.; Zhang, L.; Li, H. Polyaniline/graphene hybrid fibers as electrodes for flexible supercapacitors. Synth. Met. 2020, 268, 116484. [CrossRef]

12. Qiu, H.; Cheng, H.; Meng, J.; Wu, G.; Chen, S. Magnetothermal Microfluidic-Assisted Hierarchical Microfibers for UltrahighEnergy-Density Supercapacitors. Angew. Chem. Int. Ed. Engl. 2020, 59, 7934-7943. [CrossRef]

13. Xu, Z.; Gao, C. Graphene chiral liquid crystals and macroscopic assembled fibres. Nat. Commun. 2011, 2, 571. [CrossRef] [PubMed]

14. Li, J.; Shao, Y.; Jiang, P.; Zhang, Q.; Hou, C.; Li, Y.; Wang, H. 1T-Molybdenum disulfide/reduced graphene oxide hybrid fibers as high strength fibrous electrodes for wearable energy storage. J. Mater. Chem. A 2019, 7, 3143-3149. [CrossRef]

15. Meng, J.; Nie, W.; Zhang, K.; Xu, F.; Ding, X.; Wang, S.; Qiu, Y. Enhancing Electrochemical Performance of Graphene Fiber-Based Supercapacitors by Plasma Treatment. ACS Appl. Mater. Interfaces 2018, 10, 13652-13659. [CrossRef]

16. Li, Z.; Wei, J.; Ren, J.; Wu, X.; Wang, L.; Pan, D.; Wu, M. Hierarchical construction of high-performance all-carbon flexible fiber supercapacitors with graphene hydrogel and nitrogen-doped graphene quantum dots. Carbon 2019, 154, 410-419. [CrossRef]

17. Gao, L.; Song, J.; Surjadi, J.U.; Cao, K.; Han, Y.; Sun, D.; Tao, X.; Lu, Y. Graphene-Bridged Multifunctional Flexible Fiber Supercapacitor with High Energy Density. ACS Appl. Mater. Interfaces 2018, 10, 28597-28607. [CrossRef] [PubMed]

18. Xu, T.; Yang, D.; Fan, Z.; Li, X.; Liu, Y.; Guo, C.; Zhang, M.; Yu, Z.Z. Reduced graphene oxide/carbon nanotube hybrid fibers with narrowly distributed mesopores for flexible supercapacitors with high volumetric capacitances and satisfactory durability. Carbon 2019, 152, 134-143. [CrossRef]

19. Zhai, S.; Wang, C.; Karahan, H.E.; Wang, Y.; Chen, X.; Sui, X.; Huang, Q.; Liao, X.; Wang, X.; Chen, Y. Nano-RuO2-Decorated Holey Graphene Composite Fibers for Micro-Supercapacitors with Ultrahigh Energy Density. Small 2018, 14, e1800582. [CrossRef]

20. Zheng, X.; Zhou, X.; Xu, J.; Zou, L.; Nie, W.; Hu, X.; Dai, S.; Qiu, Y.; Yuan, N. Highly stretchable CNT/MnO 2 nanosheets fiber supercapacitors with high energy density. J. Mater. Sci. 2020, 55, 8251-8263. [CrossRef]

21. Ramesh, S.; Lee, Y.J.; Shin, K.; Sanjeeb, L.; Karuppasamy, K.; Vikraman, D.; Kathalingam, A.; Kim, H.S.; Kim, H.S.; Kim, J.H. Effect of ruthenium oxide on the capacitance and gas-sensing performances of cobalt oxide @nitrogen-doped graphene oxide composites. Int. J. Energy Res. 2021, 45. [CrossRef]

22. Ramesh, S.; Karuppasamy, K.; Vikraman, D.; Kim, E.; Sanjeeb, L.; Lee, Y.J.; Kim, H.S.; Kim, J.H.; Kim, H.S. Hierarchical Co ${ }_{3} \mathrm{O}_{4}$ decorated nitrogen-doped graphene oxide nanosheets for energy storage and gas sensing applications. J. Ind. Eng. Chem. 2021, 101, 253-261. [CrossRef]

23. Wang, C.; Zhai, S.; Yuan, Z.; Chen, J.; Zhang, X.; Huang, Q.; Wang, Y.; Liao, X.; Wei, L.; Chen, Y. A core-sheath holey graphene/graphite composite fiber intercalated with MoS2 nanosheets for high-performance fiber supercapacitors. Electrochim. Acta 2019, 305, 493-501. [CrossRef]

24. Zhou, C.; Hong, M.; Yang, Y.; Yang, C.; Hu, N.; Zhang, L.; Yang, Z.; Zhang, Y. Laser-induced bi-metal sulfide/graphene nanoribbon hybrid frameworks for high-performance all-in-one fiber supercapacitors. J. Power Sources 2019, 438, 227044. [CrossRef]

25. Vikraman, D.; Karuppasamy, K.; Hussain, S.; Kathalingam, A.; Sanmugam, A.; Jung, J.; Kim, H.S. One-pot facile methodology to synthesize $\mathrm{MoS}_{2}$-graphene hybrid nanocomposites for supercapacitors with improved electrochemical capacitance. Compos. Part B 2019, 161, 555-563. [CrossRef]

26. Luo, W.; Zhang, L.; Wang, W.; Ouyang, L.; Xue, H. Polyaniline-Modified Hierarchical Graphene Fiber for Ultrahigh-Performance Electrochemical Supercapacitor with Carbon Fiber in Core as Current Collector. Energy Technol. 2019, 7, 1900522. [CrossRef]

27. Li, P.; Jin, Z.; Peng, L.; Zhao, F.; Xiao, D.; Jin, Y.; Yu, G. Stretchable All-Gel-State Fiber-Shaped Supercapacitors Enabled by Macromolecularly Interconnected 3D Graphene/Nanostructured Conductive Polymer Hydrogels. Adv. Mater. 2018, 30, e1800124. [CrossRef]

28. Ramesh, S.; Yadav, H.M.; Karuppasamy, K.; Vikraman, D.; Kim, H.S.; Kim, J.H.; Kim, H.S. Fabrication of manganese oxide@nitrogen doped graphene oxide/polypyrrole $\left(\mathrm{MnO}_{2} @ \mathrm{NGO} / \mathrm{PPy}\right)$ hybrid composite electrodes for energy storage devices. J. Mater. Res. Technol. 2019, 8, 4227-4238. [CrossRef]

29. Zheng, J.; Miao, F.; Peng, Y.; Miao, F. The fabrication of hierarchical nanostructured graphene/PPy fiber composites and its electrochemical properties. Ionics 2020, 26, 2667-2671. [CrossRef]

30. Almeida, D.A.L.; Couto, A.B.; Ferreira, N.G. Flexible polyaniline/reduced graphene oxide/carbon fiber composites applied as electrodes for supercapacitors. J. Alloy. Compd. 2019, 788, 453-460. [CrossRef]

31. Li, Q.; Cheng, H.; Wu, X.; Wang, C.F.; Wu, G.; Chen, S. Enriched carbon dots/graphene microfibers towards high-performance micro-supercapacitors. J. Mater. Chem. A 2018, 6, 14112-14119. [CrossRef] 
32. Wu, X.; Wu, G.; Tan, P.; Cheng, H.; Hong, R.; Wang, F.; Chen, S. Construction of microfluidic-oriented polyaniline nanorod arrays/graphene composite fibers for application in wearable micro-supercapacitors. J. Mater. Chem. A 2018, 6, 8940-8946. [CrossRef]

33. Zhang, K.; Zhang, L.L.; Zhao, X.S.; Wu, J. Graphene/Polyaniline Nanofiber Composites as Supercapacitor Electrodes. Chem. Mater. 2010, 22, 1392-1401. [CrossRef]

34. Huang, T.; Cai, S.; Chen, H.; Jiang, Y.; Wang, S.; Gao, C. Continuous fabrication of the graphene-confined polypyrrole film for cycling stable supercapacitors. J. Mater. Chem. A 2017, 5, 8255-8260. [CrossRef]

35. Fan, T.; Tong, S.; Zeng, W.; Niu, Q.; Liu, Y.; Kao, C.Y.; Liu, J.; Huang, W.; Min, Y.; Epstein, A.J. Self-assembling sulfonated graphene/polyaniline nanocomposite paper for high performance supercapacitor. Synth. Met. 2015, 199, 79-86. [CrossRef]

36. Zhao, H.B.; Yang, J.; Lin, T.T.; Lu, Q.F.; Chen, G. Nanocomposites of sulfonic polyaniline nanoarrays on graphene nanosheets with an improved supercapacitor performance. Chemistry 2015, 21, 682-690. [CrossRef] [PubMed]

37. Wang, J.; Wu, Z.; Hu, K.; Chen, X.; Yin, H. High conductivity graphene-like $\mathrm{MoS}_{2}$ / polyaniline nanocomposites and its application in supercapacitor. J. Alloy. Compd. 2015, 619, 38-43. [CrossRef]

38. Guo, F.; Kim, F.; Han, T.H.; Shenoy, V.B.; Huang, J.X.; Hurt, R.H. Hydration-Responsive Folding and Unfolding in Graphene Oxide Liquid Crystal Phases. ACS Nano 2011, 5, 8019-8025. [CrossRef] [PubMed]

39. Zhang, M.; Jia, M. High rate capability and long cycle stability $\mathrm{Fe}_{3} \mathrm{O}_{4}$-graphene nanocomposite as anode material for lithium ion batteries. J. Alloy. Compd. 2013, 551, 53-60. [CrossRef]

40. Liu, H.; Du, H.L.; Zhao, W.; Qiang, X.J.; Zheng, B.; Li, Y.; Cao, B. Fast potassium migration in mesoporous carbon with ultrathin framework boosting superiorrateper formance for high-power potassium storage. Energy Stor. Mater. 2021, 40, 490-498. [CrossRef]

41. Zhang, M.; Wang, Y.; Jia, M. Three-Dimensional Reduced Graphene Oxides Hydrogel Anchored with Ultrafine CoO Nanoparticles as Anode for Lithium Ion Batteries. Electrochim. Acta 2014, 129, 425-432. [CrossRef]

42. Xu, H.; Liu, J.; Chen, Y.; Li, C.L.; Tang, J.; Li, Q. Synthesis of three-dimensional nitrogen-doped graphene/polyaniline hydrogels for high performance supercapacitor applications. J. Mater. Sci. Mater. Electron. 2017, 28, 10674-10683. [CrossRef]

43. Feng, X.; Chen, N.; Zhou, J.; Li, Y.; Huang, Z.; Zhang, L.; Ma, Y.; Wang, L.; Yan, X. Facile synthesis of shape-controlled graphene-polyaniline composites for high performance supercapacitor electrode materials. New J. Chem. 2015, 39, $2261-2268$. [CrossRef]

44. Li, H.; Song, J.; Wang, L.; Feng, X.; Liu, R.; Zeng, W.; Huang, Z.; Ma, Y.; Wang, L. Flexible all-solid-state supercapacitors based on polyaniline orderly nanotubes array. Nanoscale 2017, 9, 193-200. [CrossRef]

45. Jia, Y.; Zhang, M.; Li, H.; Wang, J.; Guan, F. Controllable synthesis and electrochemical performance of hierarchically structured graphene fibers. Mater. Chem. Phys. 2017, 193, 35-41. [CrossRef]

46. Li, X.; Zhao, T.; Chen, Q.; Li, P.; Wang, K.; Zhong, M.; Wei, J.; Wu, D.; Wei, B.; Zhu, H. Flexible all solid-state supercapacitors based on chemical vapor deposition derived graphene fibers. Phys. Chem. Chem. Phys. 2013, 15, 17752-17757. [CrossRef]

47. Cai, S.Y.; Huang, T.Q.; Chen, H.; Salman, M.; Gopalsamy, K.; Gao, C. Wet-spinning of ternary synergistic coaxial fibers for high performance yarn supercapacitors. J. Mater. Chem. A 2017, 5, 22489-22494. [CrossRef]

48. Zheng, X.; Yao, L.; Qiu, Y.; Wang, S.; Zhang, K. Core-Sheath Porous Polyaniline Nanorods/Graphene Fiber-Shaped Supercapacitors with High Specific Capacitance and Rate Capability. ACS Appl. Energy Mater. 2019, 2, 4335-4344. [CrossRef]

49. Huang, T.; Zheng, B.; Kou, L.; Gopalsamy, K.; Xu, Z.; Gao, C.; Meng, Y.; Wei, Z. Flexible high performance wet-spun graphene fiber supercapacitors. RSC Adv. 2013, 3, 23957. [CrossRef]

50. Chen, S.; Ma, W.; Cheng, Y.; Weng, Z.; Sun, B.; Wang, L.; Chen, W.; Li, F.; Zhu, M.; Cheng, H.M. Scalable non-liquid-crystal spinning of locally aligned graphene fibers for high-performance wearable supercapacitors. Nano Energy 2015, 15, 642-653. [CrossRef]

51. Li, B.; Cheng, J.; Wang, Z.; Li, Y.; Ni, W.; Wang, B. Highly-wrinkled reduced graphene oxide-conductive polymer fibers for flexible fiber-shaped and interdigital-designed supercapacitors. J. Power Sources 2018, 376, 117-124. [CrossRef]

52. Ding, X.; Zhao, Y.; Hu, C.; Hu, Y.; Dong, Z.; Chen, N.; Zhang, Z.; Qu, L. Spinning fabrication of graphene/polypyrrole composite fibers for all-solid-state, flexible fibriform supercapacitors. J. Mater. Chem. A 2014, 2, 12355. [CrossRef] 